\title{
Comparison of Cellulose Extraction from Sugarcane Bagasse Through Alkali
}

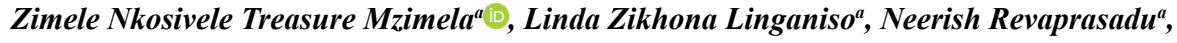

\author{
Tshwafo Elias Motaung *
}

\author{
a Department of Chemistry, University of Zululand (KwaDlangezwa Campus), Private Bag X1001, 3886, \\ South Africa
}

Received: August 22, 2018; Revised: July 27, 2018; Accepted: September 28, 2018

\begin{abstract}
This article investigated the cellulose obtained from sugarcane bagasse by five different extraction mercerization methods. The comparison of the methods gives a clearer picture of that is more effective and feasible for production of SCB cellulose. All the celluloses were characterised by X-Ray Diffraction (XRD), Fourier Transform Infrared (FT-IR), Thermal Gravimetric Analysis (TGA), Scanning Electron Microscope (SEM) and Optical Microscope (OM). All the methods led to white material resembling pure cellulose due to removal of non-cellulosic constituents as can be seen by disappearance of aromatic bands. The removal indicated a decrease in diameter and improved thermal stability in most methods. The materials in general stand a better chance of competing as fillers for polymeric composites.
\end{abstract}

Keywords: Sugar cane bagasse, extraction methods, cellulose, crystallinity.

\section{Introduction}

The extraction of cellulose from natural matrix in plants involves the removal of lignin, hemicelluloses and pectins. Over the past few years, a lot of methods have been suggested and used by different researchers to extract cellulose from different plants ${ }^{1-17}$. The methods generally involve basic or oxidative treatments that have the ability to discharge cellulose. Alternatively, treatment with peracids has been used to extract cellulose. This step is significant due to the ability to change the thermal stability and crystallinity of a cellulosic material. Other researchers used an acid-induced destructuring process, during which the heterogeneous acid hydrolysis involves the diffusion of acid molecules into cellulose fibres, followed by cleavage of glycosidic bonds. That was followed by centrifugation, dialysis and ultrasonication ${ }^{18}$. Most studies used six steps, which were the pre-treatment of the fibres with sodium hydroxide, hydrogen peroxide, sodium hydroxide and $\mathrm{Na}_{2} \mathrm{~B}_{4} \mathrm{O}_{7} \cdot 10 \mathrm{H}_{2} \mathrm{O}, \mathrm{HNO}_{3}$ and $\mathrm{HAc}$, ethanol, water and finally drying the product in an oven until constant weight. Other researchers involved the treatment of fibres with sodium chlorite which facilitated the removal of lignin, which was followed by $\mathrm{NaOH}$ and drying until constant weight ${ }^{19}$. Although both methods resulted in cellulose with significant quantities of hemicelluloses or lignin, the first procedure was less environmentally aggressive, while the second involved less process time and led to fibres with more homogeneous diameter distribution.

Treatments consisting of alkali extraction and bleaching have been the mostly used in the extraction of cellulose ${ }^{20}$. The alkali extraction treatment allows the removal of soluble polysaccharides, and the subsequent bleaching treatment removes most of the residual phenolic molecules like lignin or polyphenols.

There are lot of different methods used to extract cellulose, nonetheless the literature is virtually mute about a methodical comparison of properties from different methods and possible benefits for different applications. Five different methods of extraction of cellulose from the same sugar cane bagasse were used in this study. Characterization techniques used for comparison included TGA, FTIR, XRD, OM, and SEM.

\section{Experimental}

\subsection{Materials}

Sugarcane bagasse was obtained from a sugarcane mill in Felixton near Empangeni, South Africa. Acetic acid was obtained from Laboratory Consumables and Chemical Suppliers, sodium sulphite and sodium hydroxide were obtained from Merk, sodium chlorite was obtained from Sigma Aldrich, and sodium hypochlorite was obtained from a local supermarket. All chemicals were used without further purification, but were prepared to the desired concentrations.

\subsection{Extraction of cellulose from sugarcane bagasse}

\subsubsection{Method 1(M1)}

Sugarcane bagasse was boiled in water (4hrs). Soaked in $4 \%$ sodium hydroxide ( $4 \mathrm{hrs}$ ), followed by treating with $4 \%$ sodium hypochlorite and $2 \%$ sodium hydroxide $(4 \mathrm{hrs})$ at $100{ }^{\circ} \mathrm{C}$ before washing with distilled water to $\mathrm{pH}$ neutral. The final product was dried at room temperature for 2 days. 


\subsubsection{Method 2(M2)}

From the M1 1, $4 \%$ of sodium hypochlorite was acidified with acetic acid to $\mathrm{pH} 4$.

\subsubsection{Method 3(M3)}

From the M1, 2 and $1 \%$ of $\mathrm{NaOH}$ was used in the second and last step respectively, $0.7 \%$ sodium chlorite acidified with acetic acid to $\mathrm{pH} 4$ was used instead of $4 \%$ sodium hypochlorite.

\subsubsection{Method 4(M4)}

From the M3, the last step was eliminated.

\subsubsection{Method 5(M5)}

From the M3, the additional step was added after sodium chlorite step, in which sample was treated with 5\% sodium sulphite at $100^{\circ} \mathrm{C}$ for three hours.

\subsection{Analysis}

\subsubsection{Optical Microscopy (OM)}

The optical microscope images of the samples were viewed using a LEICA MC 120 HD microscope. Dark and bright field modes were used to capture the images at a magnification of $40 \mathrm{x} / 0.65$.

\subsubsection{Scanning Electron Microscope (SEM)}

The SEM and EDX measurements of the as-deposited thin films were performed on a Philips XL 30 FEG (at $10 \mathrm{kV}$ ) and DX4 detector (at $20 \mathrm{kV}$ ), respectively. The films were carbon-coated by using Edward's E306A coating system, prior to the analyses.

\subsubsection{Fourier Transform infrared (FTIR)}

Infra-red spectra of the samples were recorded on a Bruker FT-IR Tensor 27 spectrophotometer equipped with a standard ATR crystal cell detector. The spectra were recorded at a wavenumber range of 500-4000 $\mathrm{cm}^{-1}$.

\subsubsection{X-Ray Diffraction (XRD)}

The diffraction patterns of the cellulosic materials were investigated at room temperature using an Advanced Bruker AX D8 diffractometer in the range $2 \theta=10-90^{\circ}$, equipped with nickel-filtered $\mathrm{Cu} K \alpha$ radiation $(\lambda=1.542 \AA)$ at $40 \mathrm{kV}$ and $40 \mathrm{~mA}$. The scan speed was $0.5 \mathrm{sec} / \mathrm{step}$.

\subsubsection{Thermal Gravimetric Analysis (TGA)}

Thermogravimetric analyses were carried out using a Perkin Elmer Pyris 6 TGA equipped with a closed perforated pan at a heating rate of $10{ }^{\circ} \mathrm{C} \cdot \mathrm{min}^{-1}$. Approximately $2 \mathrm{mg}$ of each sample was heated from $30-600{ }^{\circ} \mathrm{C}$ under $\mathrm{N}_{2}$ gas flow rate of $10 \mathrm{ml} \cdot \mathrm{min}^{-1}$.

\section{Results and Discussion}

\subsection{Optical microscope}

Optical microscope images of all the methods are shown in Figure 1 (a-e). The fibres of M1 and 2 are agglomerated. In M1 the fibres are more agglomerated and closely packed than in M2. M3, 4 and 5 show defibrillation and thinning of fibres, which signal the removal of non-cellulosic components in SCB. The thinning and defibrillation is further noted for the M5.

The M1 (Figure 1a) showed agglomeration compared to M2. This is because sodium hypochlorite is highly basic in nature and therefore could not effectively facilitate the digestion of the cell walls which is meant to make the treatment with alkali more effective. The introduction of acetic acid in sodium hypochlorite in M2 (Figure 1b) increased the defibrillation, but to a very small extent.

In M3, 4 and 5 (Figure $1 \mathrm{c}-\mathrm{e}$ ), acidified sodium chlorite was used for the digestion of the cell walls of SCB. This proved to be more effective than M1 and M2. Further defibrillation was noted for the M5 (Figure 1e) and can be attributed to sodium sulphite used for dissolved lignin-chlorine complex that forms during the digestion process.

\subsection{Scanning Electron Microscope (SEM)}

Figure 2 showed SEM micrographs of raw sugarcane bagasse ( $\mathrm{a}$ and $\mathrm{b}$ ) ranging from 100 to $250 \mu \mathrm{m}$. There are many non- fibrous materials, from waxes and pectin, which are scattered over the surface. The SEM micrographs of the different methods used for the extraction of cellulose from sugarcane bagasse are shown in Figures 3, 4 and 5. The surfaces of all the cellulosic materials are cleaner and a bit rougher in comparison to those of raw bagasse. Furthermore, individual fibres show a decrease in diameter from about 3 to $10 \mu \mathrm{m}$, which signify the removal of hemicelluloses, lignin, pectins and waxes.

As the bagasse is treated with different chemicals, the non-cellulosic components are removed to promote defibrillation, which causes reduction in diameter. SEM results are in correspondence with observations made from the optical microscope analysis.

\subsection{Fourier Transform infrared (FTIR)}

Figure 6 represents FT-IR spectra of extracted cellulosic materials. For all the samples, the FTIR spectra showed O-H stretching broad band at $3500-3200 \mathrm{~cm}^{-1}$. The spectra also showed C-H stretching vibration at around $2894 \mathrm{~cm}^{-1}$, which is also characteristic of cellulosic materials. Absorbance peaks around $1649-1641 \mathrm{~cm}^{-1}$ resulted from O-H bending of adsorbed water. The peaks around $1054 \mathrm{~cm}^{-1}$ are due to the $\mathrm{C}-\mathrm{O}-\mathrm{C}$ pyranose ring stretching vibration ${ }^{10}$. Another important absorption band is at around $902 \mathrm{~cm}^{-1}$ which is associated with the $\beta$-glycosidic linkages between glucose ${ }^{6,9,13}$. 

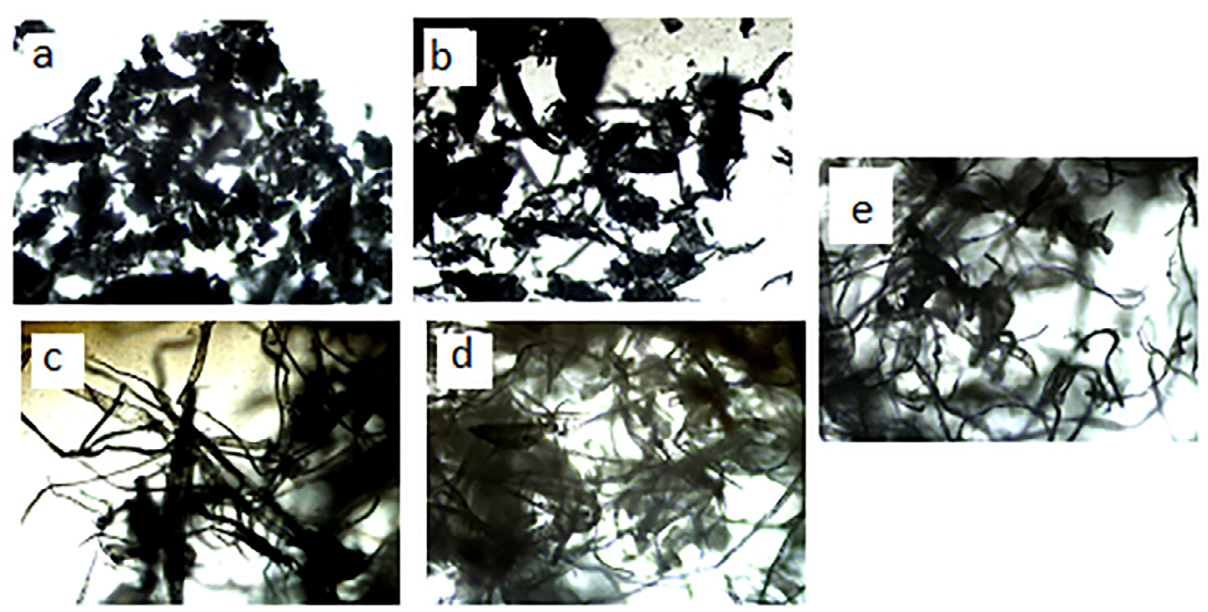

Figure 1. OM images of methods 1(a), 2(b), 3(c), 4(d), and 5(e)
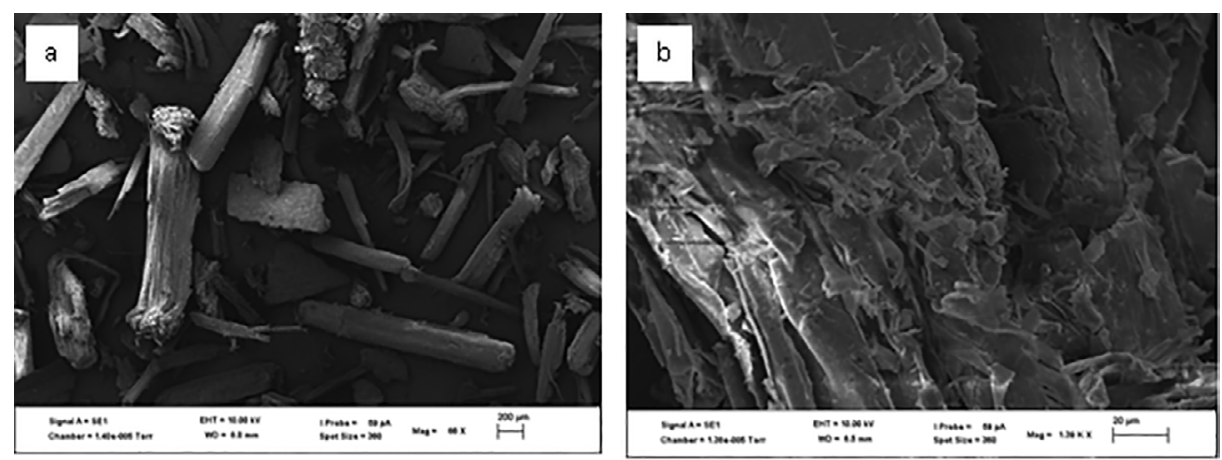

Figure 2. SEM micrographs of raw sugarcane bagasse
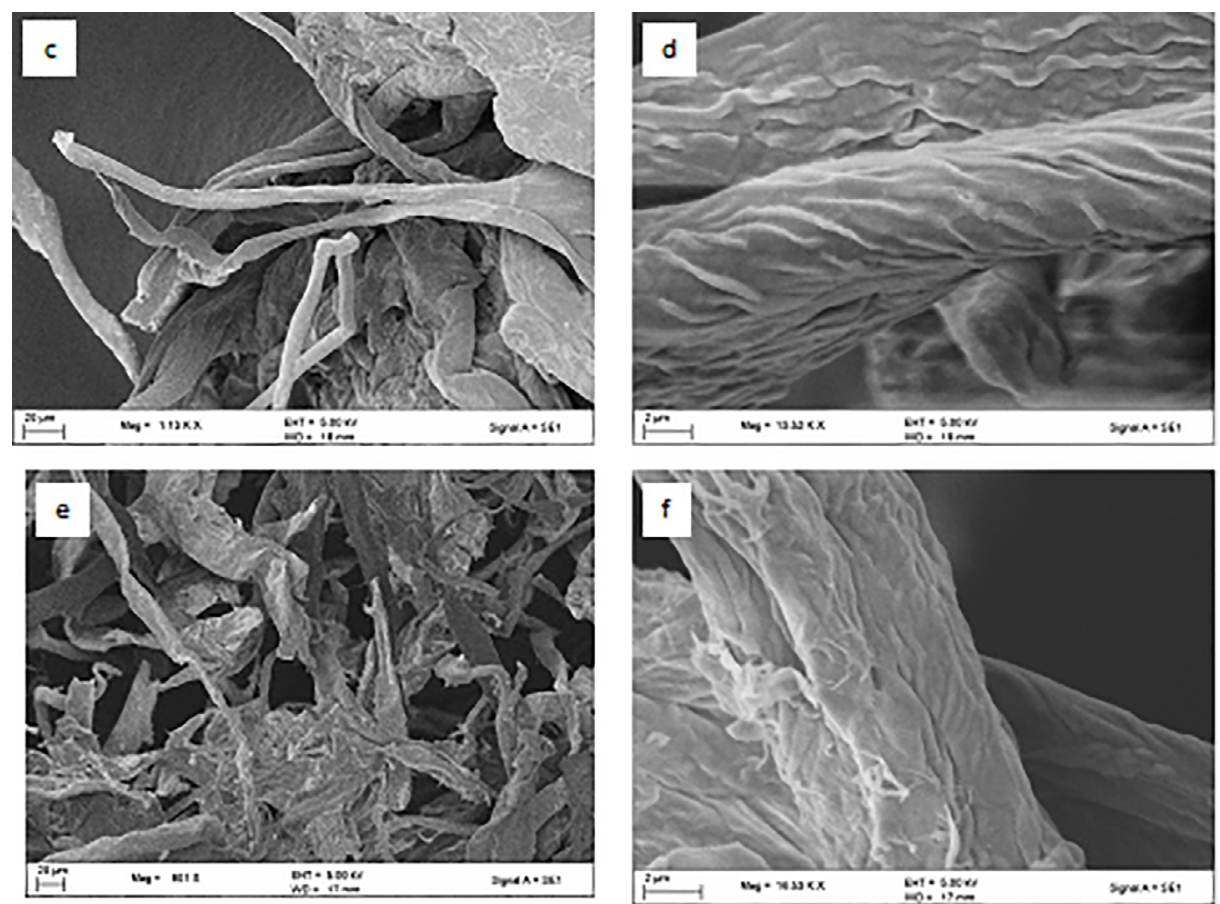

Figure 3. SEM micrographs of cellulose extracted from sugarcane bagasse through method 1 (c, d), method 2 (e, f) 

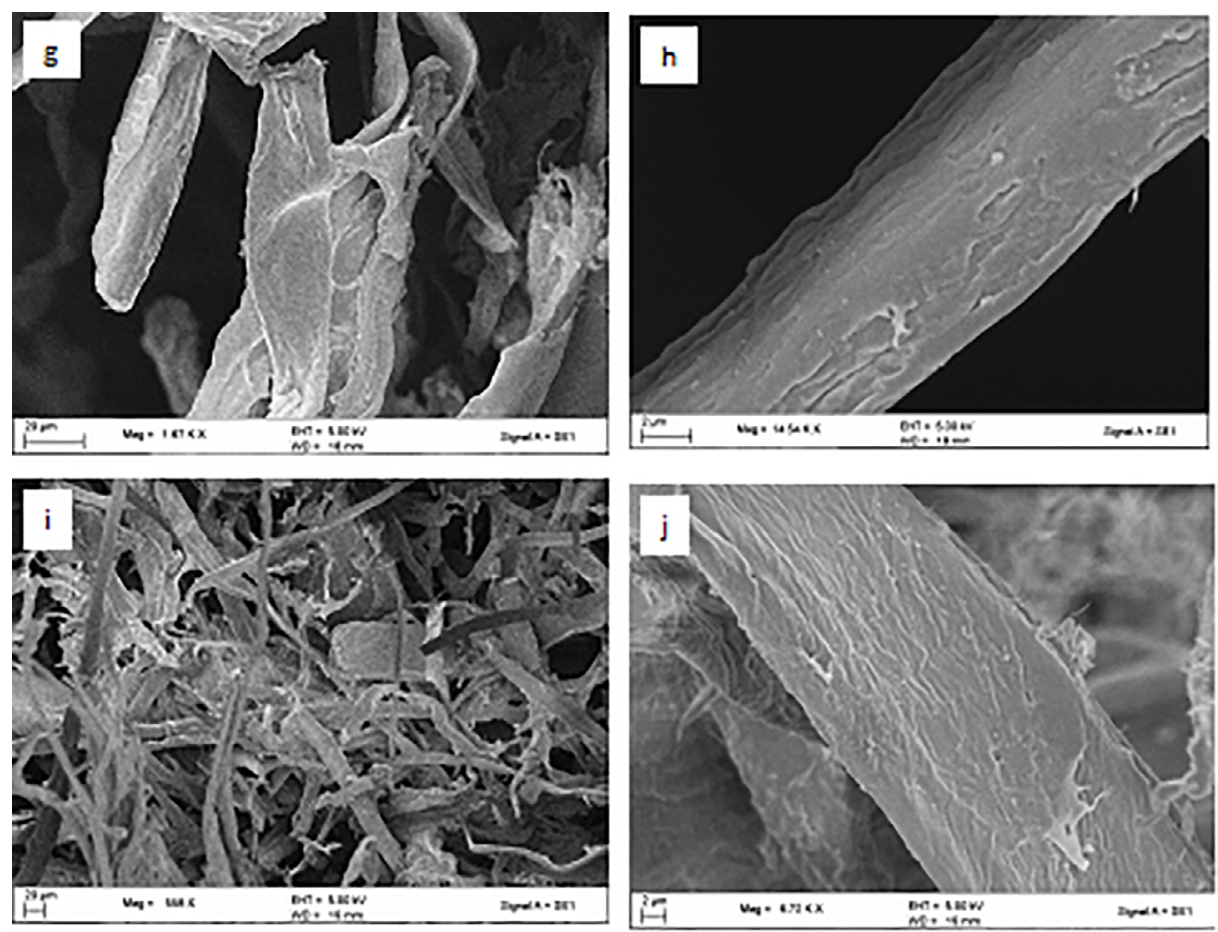

Figure 4. SEM micrographs of cellulose extracted from sugarcane bagasse through method $3(\mathrm{~g}, \mathrm{~h})$ andmethod $4(\mathrm{i}, \mathrm{j})$
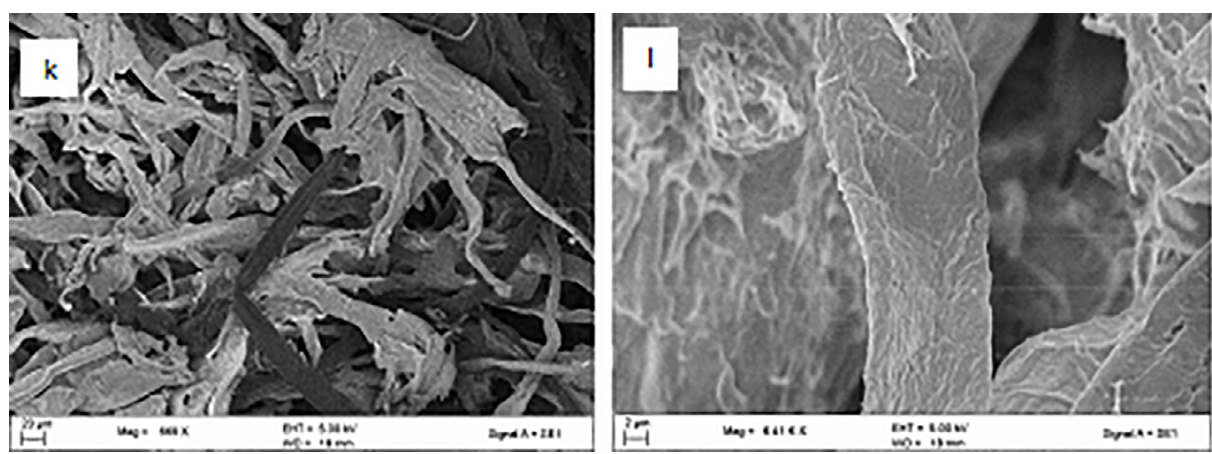

Figure 5. SEM micrographs of cellulose extracted from sugarcane bagasse through method 5
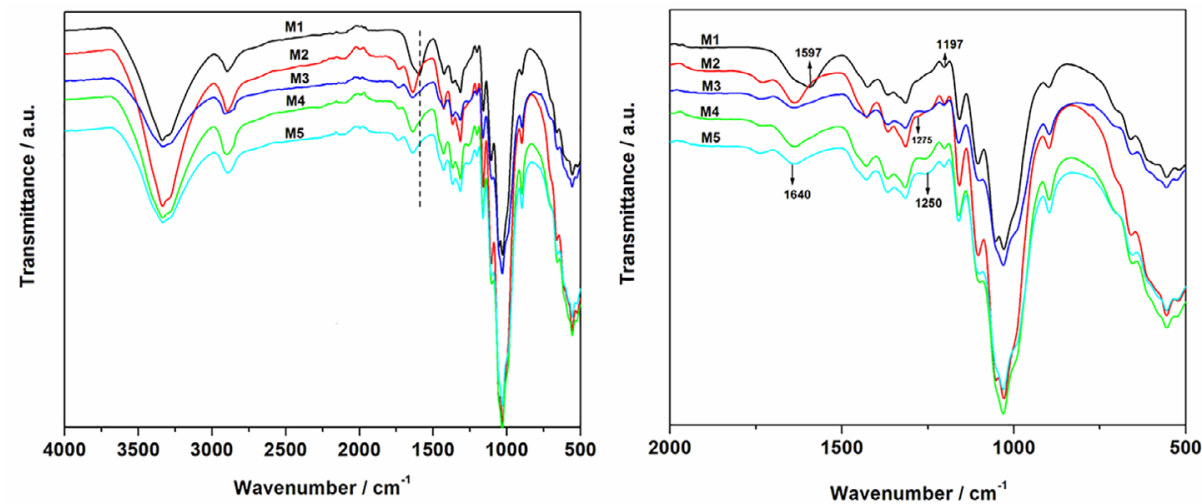

Figure 6. FTIR spectra of the methods used for the extraction of cellulose from sugarcane bagasse 
The M1 revealed low O-H stretching band compared to the rest, except M3 which showed the lowest. Furthermore, it revealed the aromatic peak at $1597 \mathrm{~cm}^{-1}$, whereas other were reflected almost at $1640 \mathrm{~cm}^{-1}$. The $\mathrm{O}-\mathrm{H}$ stretching band for M2 is more intense than all and not showing a peak at 1250 $\mathrm{cm}^{-1}$ compared to the rest. As for M3, most of the aromatic peaks (e.g. $1197 \mathrm{~cm}^{-1}$ ) have almost disappeared. The M4 and M5 followed the same trend as M3, even though their peaks are slightly intense than $\mathrm{M} 3$ including $\mathrm{O}-\mathrm{H}$ stretching.

\subsection{X-Ray Diffraction}

All the diffractograms at high reflection of the five methods are displayed in Figure 7. Crystallinity index (CI) values were calculated from the Segal empirical method ${ }^{22}$. The CI values calculated from the height of the 002 peak $\left(\mathrm{I}_{002}\right)$ and the height of the minimum $\left(\mathrm{I}_{\text {min }}\right)$ between the 002 peak and the 001 peaks. The crystallite sizes were calculated using Scherrer equation ${ }^{22}$.Very well-defined peaks at around $2 \theta=12.5^{\circ}$ (for 110 planes) and $2 \theta=22.5^{\circ}$ (for 200 planes), which are representative of a typical cellulose structure. However, M1 and M2 revealed impurities which seemed to have a little or/and no relation with the structure of cellulose. Surprisingly they have almost the same crystallite size. The same is apparent for a reflection at approximately $61^{\circ}$ for M4 and M5. These indicated either formation or presence of cellulose derivatives from the chlorite salts ${ }^{5,7,18}$. Furthermore, crystallinity index values of M4 and M5 dominated the rest followed by M2, M3 and M1 (See Table 1).

The use of $\mathrm{NaOH}$ after the chlorite salts for M1, M2 M3 promoted formation of cellulose derivatives which rendered the decreased crystallite index value. This is in line with literature which indicated that formation of some cellulose derivatives is known to decrease initial crystallinity $5,7,18,19,21$. In fact, the difference in crystallinity of M1, M2 and M3 could be safely attributed to potential of the chlorite salts. For example, the M2 suggested that the use of $0.7 \%$ acidic sodium chlorite over acidic sodium hypochlorite in M3 was adverse to obtain high crystallinity but resolute to maintain the cellulose structure. Coincidentally M3,M4 and M5 appeared to have almost similar crystalline sizes which are less than M1 and M2 within experimental uncertainties. The
Table 1. Crystallinity index and Crystallite size values of the methods.

\begin{tabular}{lccc}
\hline Method & $\begin{array}{c}2 \theta \text { (Main } \\
\text { reflection) }\end{array}$ & $\begin{array}{c}\text { Crystallinity } \\
\text { index }(\%)\end{array}$ & $\begin{array}{c}\text { Crystallite size } \\
(\mathrm{nm})\end{array}$ \\
\hline M1 & 23.08 & 68 & $5.2 \pm 2.1$ \\
M2 & 22.98 & 70 & $5.0 \pm 1.5$ \\
M3 & 22.63 & 67 & $3.9 \pm 0.4$ \\
M4 & 23.32 & 72 & $3.8 \pm 1.2$ \\
M5 & 22.63 & 73 & $4.0 \pm 2.2$ \\
\hline
\end{tabular}

inconsistency in crystalline sizes versus crystallinity index particularly under different treatments of cellulosic material is known in literature and that account for our observations ${ }^{22}$. Nonetheless in this study an unsafe inference could be drawn that the increase in crystallinity index of cellulosic material is indirectly proportional to crystallite size.

\subsection{Thermal Gravimetric Analysis}

Figure 8 represented TG and DTG curves of cellulose extracted from the different methods. All curves appeared to follow similar degradation mechanism with three degradation steps. The second step shouldered the third, except M1 which indicated a resolution of the second and third steps at approximately 250 and $300^{\circ} \mathrm{C}$. In addition M1 indicated poorest thermal stability with highest char content, while M5 and M3 revealed higher thermal stability trailed by M4 and M2 respectively. This results seem to contradict SEM which suggested a better surface area for M1, but FTIR and XRD suggested formation cellulose derivatives. It is known in literature that lignin is catalytic to thermal degradation of celluloses ${ }^{13,16}$, but in this case the derivatives seemed to dominate because all samples indicated presence of lignin from FTIR. By the way another factor may be the lignin content or the nature of cellulose derivative which could explain higher thermal stabilities of the other methods.

\section{Conclusions}

Cellulose has been successfully extracted from sugarcane bagasse through five different methods. The use of acidified sodium chlorite proved to be very effective in the digestion of
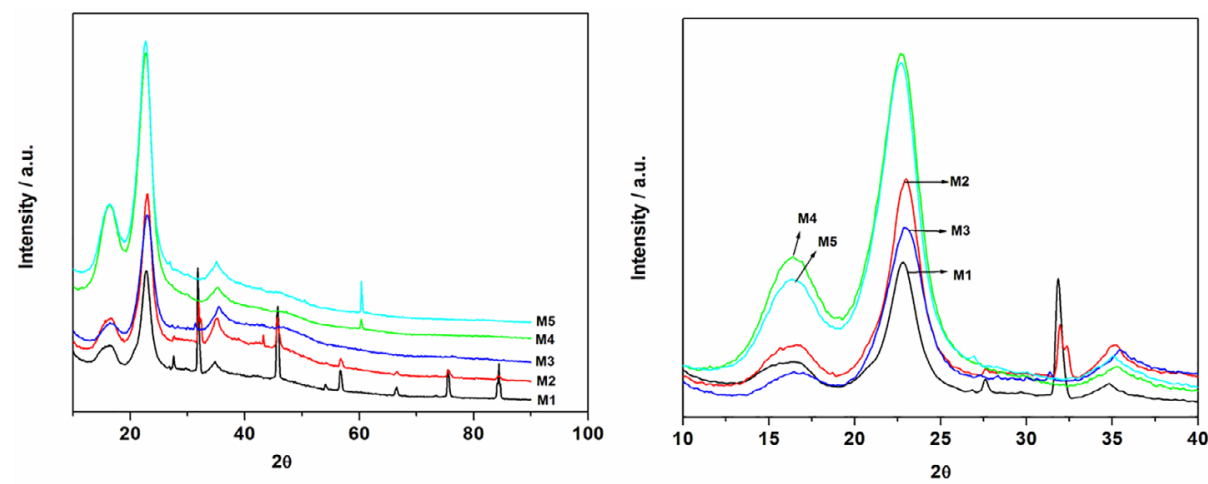

Figure 7. XRD diffractograms of the five methods used for the extraction of cellulose from sugarcane Bagasse 

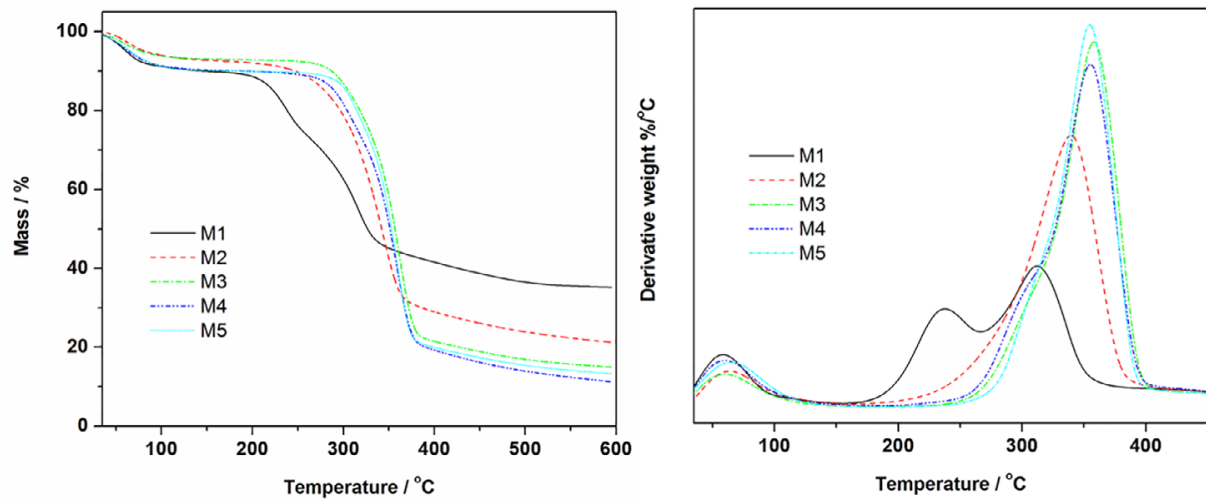

Figure 8. TG and DTG curves of the five methods used for the extraction of cellulose from sugarcane bagasse

SCB cell walls in contrast to the use of sodium hypochlorite. Acidified sodium hypochlorite yielded better results than its non-acidified counterpart. Characterization techniques showed cellulose extracted through the M5 to have crystallinity trailed by M4. In fact generally the crystalline size is reasonably within nano range. The M5 and M3 revealed higher thermal stability lagged by M4 and M2 respectively. The properties are ideal and recommended for an application as fillers in the polymeric composites.

\section{Acknowledgement}

The authors are grateful to the National Research Foundation (NRF) through the South African Research Chair initiative (SARChi) in UNIZULU.

\section{References}

1. Phinichka N, Kaenthong S. Regenerated cellulose from high alpha cellulose pulp of steam-exploded sugarcane bagasse. Journal of Materials Research and Technology. 2018;7(1):55-65.

2. Reddy PJ, Rhim JW. Extraction and Characterization of Cellulose Microfibers from Agricultural Wastes of Onion and Garlic. Journal of Natural Fibers. 2018;15(4):465-473.

3. Althues H, Henle J, Kaskel S. Functional inorganic nanofillers for transparent polymers. Chemical Society Reviews. 2007;36(9):1454-1465.

4. Landry V, Alemdar A, Blachet P. Nanocrystalline Cellulose: Morphological, Physical, and Mechanical Properties. Forest Production Journal. 2011;61(2):104-112.

5. Maepa CE, Jayaramudu J,Okonkwo JO,Ray SS, Sadiku ER, Ramontja J. Extraction and Characterization of Natural Cellulose Fibers from Maize Tassel. International Journal of Polymer Analysis and Characterization. 2015;20(2):99109.
6. Ray SS, Okamoto M. Polymer/layered silicate nanocomposites: a review from preparation to processing. Progress in Polymer Science. 2003;28:1539-1641.

7. Habibi Y, Luca LA, Rojas OJ. Cellulose Nanocrystals: Chemistry, Self-Assembly, and Applications. Chemical Reviews. 2010;110(6):34793500 .

8. Peresin MS, Habibi Y, Vesterinen A, Rojas OJ, Pawlak JJ, Seppälä JV. Effect of Moisture on Electrospun Nanofiber Composites of Poly(vinyl alcohol) and Cellulose Nanocrystals. Biomacromolecules. 2010;11(9):2471-2477.

9. Rosa SML, Rehman N, de Miranda MIG, Nachtigall SMB, Bica CID. Chlorine-free extraction of cellulose from rice husk and whisker isolation. Carbohydrate Polymer. 2012;87(2):1131-1138.

10. Mandal A, Chakrabarty D. Isolation of nanocellulose from waste sugarcane bagasse (SCB) and its characterization. Carbohydrate Polymer. 2011;86(3):1291-1299.

11. KumarA, Singh Negi Y, Chadhary V, Bhardwaj NK. Characterization of Cellulose Nanocrystals Produced by Acid-Hydrolysis from Sugarcane Bagasse as Agro-Waste. Journal of Materials Physics and Chemistry. 2014;2(1):1-8.

12. Liu R, Yu H, Huang Y. Structure and morphology of cellulose in wheat straw. Cellulose. 2005;12(1):25-34.

13. Alemdar A, Sain M. Isolation and characterization of nanofibers from agricultural residues: wheat straw and soy hulls. Bioresorce Technology. 2008;99(6):1664-1671.

14. Zhou YM, Fu SY, Zheng LM, Zhan HY. Effect of nanocellulose isolation techniques on the formation of reinforced poly(vinyl alcohol) nanocomposite films. eXPRESS Polymer Letters. 2012;6(10):794804.

15. Han G, Huan S, Han J, Zhang Z, Wu Q. Effect of Acid Hydrolysis Conditions on the Properties of Cellulose Nanoparticle-Reinforced Polymethylmethacrylate Composites. Materials. 2014;7(1):16-29.

16. Cherian M, Leão AL, de Souza SF, Thomas S, Pothan LA, Kottaisamy $M$. Isolation of nanocellulose from pineapple leaf fibres by steam explosion. Carbohydrate Polymers. 2010;81(3):720-725. 
17. Kagarzadeh H, Ahmad I, Abdullah I, Dufresne A, Zainudin SY, Sheltami RM. Effects of hydrolysis conditions on the morphology, crystallinity, and thermal stability of cellulose nanocrystals extracted from kenaf bast fibers. Cellulose. 2012;19(3):855-866.

18. Mariano M, El Kissi N, Dufresne A. Cellulose nanocrystals and related nanocomposites: Review of some properties and challenges. Journal of Polymer Science Part B: Polymer Physics. 2014;52(12):791-806.

19. Morán JI, Alvarez VA, Cyras VP, VázquezA. Extraction of cellulose and preparation of nanocellulose from sisal fibers. Cellulose. 2008;15(1):149-159.
20. Norman AG, Jenkins SH. A new method for the determination of cellulose, based upon observations on the removal of lignin and other encrusting materials. Biochemical Journal. 1993;27(3):818-831.

21. Mwaikambo LY, Ansell MP. Chemical modification of hemp, sisal, jute, and kapok fibers by alkalization. Journal of Applied Polymer Science. 2002;84(12):2222-2234.

22. Motaung TE, Linganiso LZ, Kumar R, Anadjiwala RD. Agave and sisal fibre-reinforced polyfurfuryl alcohol composites. Journal of Thermoplastic Composite Materials. 2016;30(10):1323-1346. 